\title{
Particle mixing by the polychaete Capitella species 1: coupling fate and effect of a particle-bound organic contaminant (fluoranthene) in a marine sediment
}

\author{
Susanne D. Madsen ${ }^{1,2}$, Thomas L. Forbes ${ }^{2, *}$, Valery E. Forbes ${ }^{1}$ \\ 'Department of Life Sciences and Chemistry, Roskilde University, PO Box 260, DK-4000 Roskilde, Denmark \\ ${ }^{2}$ Department of Marine Ecology, National Environmental Research Institute, PO Box 358, Frederiksborgvej 399, \\ DK-4000 Roskilde, Denmark
}

\begin{abstract}
Particle mixing by the polychaete Capitella sp. 1 was investigated in a $22 \mathrm{~d}$ microcosm experiment in the presence and absence of the sediment-bound polycyclic aromatic hydrocarbon (PAH) fluoranthene. Mixing by Capitella sp. 1 (30000 ind. $\mathrm{m}^{-2}$ ) was examined using glass bead tracers (diam. $=30$ to $100 \mu \mathrm{m}$ ) with and without a pulse introduction of fluoranthene to the sediment surface. Worms had a profound effect on the sediment appearance and reworked sediment in a conveyor-belt fashion. The predominant mode of mixing was bioadvective, and the worms created a subsurface maximum in the glass bead tracer profiles. Glass bead subduction rates were 0.37 and $0.30 \mathrm{~mm} \mathrm{~d}^{-1}$ in uncontaminated and contaminated sediments, respectively. The reduced subduction rate $(19 \%)$ was a significant effect of fluoranthene $(\sim 10 \mathrm{ppm}$, uppermost $3 \mathrm{~mm})$, indicating that this parameter is quite sensitive to pollutant stress. The fate of particle-bound fluoranthene was also examined in sediments in the presence and absence of worms. More than half $(63 \%)$ of the fluoranthene was lost from worminhabited sediments, twice that lost from worm-free treatments. The strikingly different depth profiles of the glass-bead tracer particles versus the particle-bound fluoranthene at the end of the experiment demonstrated that macrofauna can readily decouple the fate of mineral grains and refractory organic contaminants such as fluoranthene. This decoupling was shown to occur over very short time (days to weeks) and spatial $(\mathrm{mm}$ to $\mathrm{cm}$ ) scales in the presence of worms. Contaminants may be recycled to the sediment surface by conveyor-belt feeding, and a reduced subduction rate will reduce the downward transport, keeping the contaminants nearer the sediment surface, leading to greater diffusional loss, continued recycling through deposit-feeder guts, and increased probability of resuspension. The net effect of these processes will likely result in increased degradation rates and greater bioavailability than would otherwise be the case. This investigation demonstrates that sediments do not always act as a sink and that infaunal feeding behavior can be a very important factor controlling the ultimate fate of organic contaminants.
\end{abstract}

KEY WORDS: Particle mixing - Conveyor-belt feeding C Capitella sp. 1 Infauna Sediment - Organic contaminants Fluoranthene - Microcosm

\section{INTRODUCTION}

There is increasing concern today regarding the fate and effect of anthropogenically derived pollutants in the aquatic environment. Bottom sediments often act as a sink by accumulating contaminants which are tightly adsorbed to particle surfaces from the water column and may constitute an important source of

\footnotetext{
·Addressee for correspondence.E-mail: tf@hami1.dmu.dk
}

contaminants as well (Reynoldson 1987, Landrum \& Robbins 1990). Whether sediment-associated contaminants remain buried in the seabed, degrade, enter food webs or are released to the water column depends in large measure upon the activities of deposit-feeding macrobenthos. Fate and effect are 2 equally important aspects of the problem of anthropogenic contamination, but previous studies have tended to deal individually with either fate (e.g. Helmstetter \& Alden 1994) or effect (e.g. Swartz et al. 1990) of organic contami- 
nants in aquatic ecosystems and have largely neglected the influence of resident benthic infauna (Forbes \& Forbes 1994). Fate and effect of organic contaminants vary with physical and chemical properties of the sediment (e.g. Landrum \& Robbins 1990), and infauna are known to alter sediment properties by feeding, irrigating and constructing tubes and burrows (e.g. Rhoads 1974, Aller 1982, Krantzberg 1985). Some of the most important changes in sediment properties are alterations of stratigraphy, porosity, particle size, reaction rate distributions, fluxes and porewater solute transport and diffusion rates. These effects are not independent, and often chemical changes are a consequence of the physical manipulation of sediments by infauna. In addition, chemically important changes in microbial abundance and activity are often a consequence of both chemical and physical changes brought about by organisms (Yingst \& Rhoads 1980, Aller \& Aller 1986).

Biological sediment mixing increases vertical and horizontal sediment transport, and models of the relationship between bioturbation and diagenesis of particle-bound chemical species predict that increased bioturbation can increase the accumulation of contaminants in the sediment by trapping horizontally-transported resuspended material (Aller 1982, Forbes \& Forbes 1994). Thus bioturbating infauna may often act to increase their own exposure to sediment-associated contaminants (Forbes \& Forbes 1994). Moreover, the presence of bioturbating infauna may stimulate microbial degradation of sedimentary contaminants (Gardner et al. 1979, Bauer et al. 1988). This means that infauna have the potential to indirectly control the effect of pollutants on themselves by influencing the fate of pollutants in their immediate environment.

Polycyclic aromatic hydrocarbons (PAH) comprise a group of widespread organic pollutants in aquatic environments (Neff 1979, Johnson \& Larsen 1985, Eisler 1987). Concern over the fate and effects of PAH is due to their persistence (Neff 1985, Eisler 1987), ability to bioaccumulate (Weston 1990, Clements et al. 1994), acute toxicity (Swartz et al. 1990, Landrum et al. 1991) and potential carcinogenicity (Malins et al. 1987. Metcalfe et al. 1988). PAH are mainly formed as products from the combustion of fossil fuels but also occur as natural constituents of unaltered fossil fuels. The most important sources of PAH to the aquatic environment are atmospheric fallout, spillage and seepage of petroleum/oil and industrial and domestic sewage (Neff 1985, Cerniglia \& Heitkamp 1989). Due to their hydrophobic properties PAH are highly insoluble in water and tend to associate with particulate organic material (Neff 1979, Cerniglia \& Heitkamp 1989). Bioavailability and toxicity of PAH are closely related to sedimentary organic carbon content and particle size (Swartz et al. 1990, DeWitt et al. 1992). The bio- degradation of PAH is strongly dependent on the presence of oxygen (Bauer \& Capone 1985), and they become increasingly refractory under reducing conditions (Hambrick et al. 1980, DeLaune et al. 1981).

The deposit-feeding polychaete genus Capitella consists of a group of opportunistic species typically found in organically-enriched sediments (Tsutsumi 1987, 1990. Tsutsumi et al. 1990, 1991). These worms have been found dominating the benthic fauna from sediments near refinery outfalls (Oyenekan 1983) and after oil spills (Grassle \& Grassle 1974, Sanders et al. 1980). The genus, formerly described as Capitella capitata, consists of numerous sibling species of which Capitella sp. 1 is considered to be the most opportunistic (Grassle \& Grassle 1974). The dominance of Capitella sp. 1 in oil-contaminated sediments indicates that this polychaete is able to live in sediment with relatively high concentrations of $\mathrm{PAH}$.

This investigation focuses on the interaction between bioturbating Capitella and an organic sedimentary contaminant (fluoranthene) and is a part of a larger study dealing exclusively with the interactions of Capitella sp. 1 and fluoranthene (Forbes et al. 1996. Holmer et al. in press). Capitella sp. 1 was chosen because of its opportunistic nature and frequent occurrence in oil-contaminated sediments. Fluoranthene (FLU) was selected because it is one of the most abundant PAH in sediments (Shiaris \& Jambard-Sweet 1986 ) and is known to be very toxic to some benthic invertebrates (Swartz et al. 1990).

This experiment was designed to investigate (1) the tempo and mode of particle mixing by Capitella sp. 1 . as well as how mixing is influenced by a pulse introduction of FLU to the sediment, and (2) how particle mixing by Capitella sp. 1 affects the fate of FLU within the sediment. A priori we expected Capitella to mix sediment diffusively without a strongly directional bioadvective component (Aller 1982, Rhoads \& Boyer 1982). These questions were approached by (1) quantifying the vertical mixing of an inert particle tracer in contaminated and uncontaminated microcosms and (2) measuring the concentration and vertical distribution of FLU in sediments with and without Capitella sp. 1.

\section{MATERIALS AND METHODS}

Sediment for this study was collected from a shallow subtidal site in Roskilde Fjord south of Risø, Denmark The sediment was wet sieved $(<1 \mathrm{~mm})$ in the field to remove macrobenthos and other large material. The sediment was further sieved in the laboratory to $<125 \mu \mathrm{m}$ and kept frozen $\left(-18^{\circ} \mathrm{C}\right)$ until use. The particle size-distribution of the sediment is shown in Table 1 and the contents of particulate organic matter 
Table 1. Sedimentary particle size distribution in experimental microcosms

\begin{tabular}{|lcc|}
\hline Sediment & Size fraction & $\%$ \\
\hline Very fine sand & $63-125 \mu \mathrm{m}$ & 63.20 \\
Silt & $36-63 \mu \mathrm{m}$ & 16.80 \\
Clay & $<36 \mu \mathrm{m}$ & 20.00 \\
\hline
\end{tabular}

Table 2. Experimental sediment particulate characteristics. Particulate organic matter (POM) was determined by loss on ignition $\left(550^{\circ} \mathrm{C}\right.$ for $\left.6 \mathrm{~h}\right)$. Particulate organic carbon (POC) and nitrogen (PON) were determined using an autoanalyzer interfaced to a continuous-flow isotope-ratio mass spectrometer (ANA-MS method; Jensen 1991) (mean C:N = 11.2)

\begin{tabular}{|lcr|}
\hline & \% of dry wt $\pm \mathrm{SD}$ & $\mathrm{n}$ \\
\hline POM & $4.7 \pm 0.15$ & 11 \\
POC & $2.13 \pm 0.02$ & 4 \\
PON & $0.19 \pm 0.002$ & 4 \\
\hline
\end{tabular}

(POM), particulate organic carbon (POC), and particulate organic nitrogen (PON) are shown in Table 2

Capitella sp. 1 were reared in the laboratory in $10 \mathrm{l}$ aerated aquaria at room temperature $\left(18\right.$ to $\left.22^{\circ} \mathrm{C}\right)$ and a salinity of 28 to $30 \%$ on sediment treated as described above. Ground catfood (Whiskas ${ }^{\text {TM }}$ ) was added periodically as a supplementary food source.

Preparation of particle tracer and contaminated sediment. To follow particle movement we used spherical glass beads (diam. 30 to $100 \mu \mathrm{m}$; specific gravity 2.50 to 2.55; Polysciences Inc., Washington). The beads were soaked in seawater for $24 \mathrm{~h}$ before use to obtain a biofilm. A fluoranthene stock solution was made by dissolving crystalline fluoranthene $(98 \%$ GC grade, Aldrich, Steinheim, Germany) in acetone. Using acetone as a carrier has been demonstrated to have no effect on Capitella growth rates in another study in our laboratory (Foss unpubl.). Contaminated sediment was made by adding a known volume of the fluoranthene stock solution to a known volume of sediment and glass beads. Sediment and glass beads were mixed approximately $2: 1$ on a dry weight basis The sediment/glass bead slurry was then shaken for $62 \mathrm{~h}$ at $16^{\circ} \mathrm{C}$ in the dark. After being allowed to settle for $4 \mathrm{~h}$, the overlying water was siphoned off and fresh seawater $(0.2 \mu \mathrm{m}$ filtered) was added. The sediment/glass bead slurry had a concentration of $106 \mu \mathrm{g}$ FLU $g^{-1}$ dry wt sed. (SD $\left.=5.8, \mathrm{n}=4\right)$ which is within the range of concentrations occurring in polluted harbor sediments (Shiaris \& Jambard-Sweet 1986, Shiaris 1989). The nominal porewater fluoranthene concentration was estimated to be $55 \mathrm{~g} \mathrm{FLU} \mathrm{l}^{-1}$ based on equilibrium partitioning calculations (Swartz et al.
1990, DeWitt et al. 1992) using a particulate organic carbon content of $1.4 \%$ (after glass bead dilution), a sediment concentration of $106 \mu \mathrm{g}$ FLU g ${ }^{-1}$ dry wt sed., and an organic carbon/water partition coefficient (KOC) for fluoranthene of $10^{5}(\log \mathrm{KOC}=4.92$, Karickhoff 1981). LC 50 values for Capitella have not been determined, but for amphipod crustaceans they are in the range of 15 to $50 \mu \mathrm{g} \mathrm{FLU} \mathrm{l^{-1 }}$ (Swartz et al. 1990). Uncontaminated sediment was mixed with glass beads approximately $2: 1$ on a dry weight basis and shaken for $62 \mathrm{~h}$ at $16^{\circ} \mathrm{C}$ in the dark

Experimental setup. The experiment was conducted in microcosms $(500 \mathrm{ml}$ glass beakers, $7.8 \mathrm{~cm}$ inner diameter, with rubber stoppers), each containing ca $5 \mathrm{~cm}$ of thawed sediment $(\sim 400 \mathrm{~g}$ wet $w \mathrm{t})$ and $\mathrm{ca} 5 \mathrm{~cm}$ $(\sim 100 \mathrm{ml})$ glass-fiber filtered (Whatman GF/F) seawater (26 to $33 \%$ ), with continuous aeration supplied by an airstone attached to a pump, at $13 \pm 1^{\circ} \mathrm{C}$. The microcosms were allowed to acclimate for $1 \mathrm{wk}$ without worms until an oxidized layer of a few millimeters had developed on the sediment surface. Each of the 18 microcosms was randomly assigned to 1 of 4 treatments (Fig, 1). To 12 of the 18 microcosms, 150 adult worms (avoiding females with eggs) were added yielding a worm density of 30000 ind. $\mathrm{m}^{-2}$. The microcosms were allowed to acclimate for 1 mo with worms. During the acclimation period, $3 / 4$ of the overlying water was exchanged every day with fresh, aerated seawater. After particle tracer and contaminant addition, the water was not changed. In order to maintain a constant salinity despite some evaporation, demineralized water was added to adjust salinity. Prior to the pulse introduction of contaminant and tracer, the organic carbon and nitrogen content of the sediment were checked in 2 microcosms. No noticeable change had occurred during the acclimation period. The organic carbon content was $2.02 \%(\mathrm{SD}=0.024, \mathrm{n}=2)$ and $\mathrm{C}: \mathrm{N}=11.2$ as determined by the ANA-MS method (Jensen 1991).

Both the contaminated and uncontaminated sediment/glass bead slurries, which had been previously frozen into slices $7.5 \mathrm{~cm}$ in diameter and 1 to $2 \mathrm{~mm}$ thick, were thawed and gently deposited directly on the sediment surface of each microcosm (9 microcosms for each treatment, see Fig. 1). The experiment was maintained in darkness to prevent photodegradation of fluoranthene and was run for $22 \mathrm{~d}$. Upon termination of the experiment the worms were collected, counted and allowed to empty their guts for at least $6 \mathrm{~h}$. Eleven individuals from each microcosm were measured to estimate average worm length. Worms were dried at $105^{\circ} \mathrm{C}$ for $20 \mathrm{~h}$ and weighed to obtain biomass.

Sampling and analysis of glass bead distribution. Plastic drinking straws (diam. $5 \mathrm{~mm}$ ) were used to take triplicate subcores at the end of the experiment in 3 


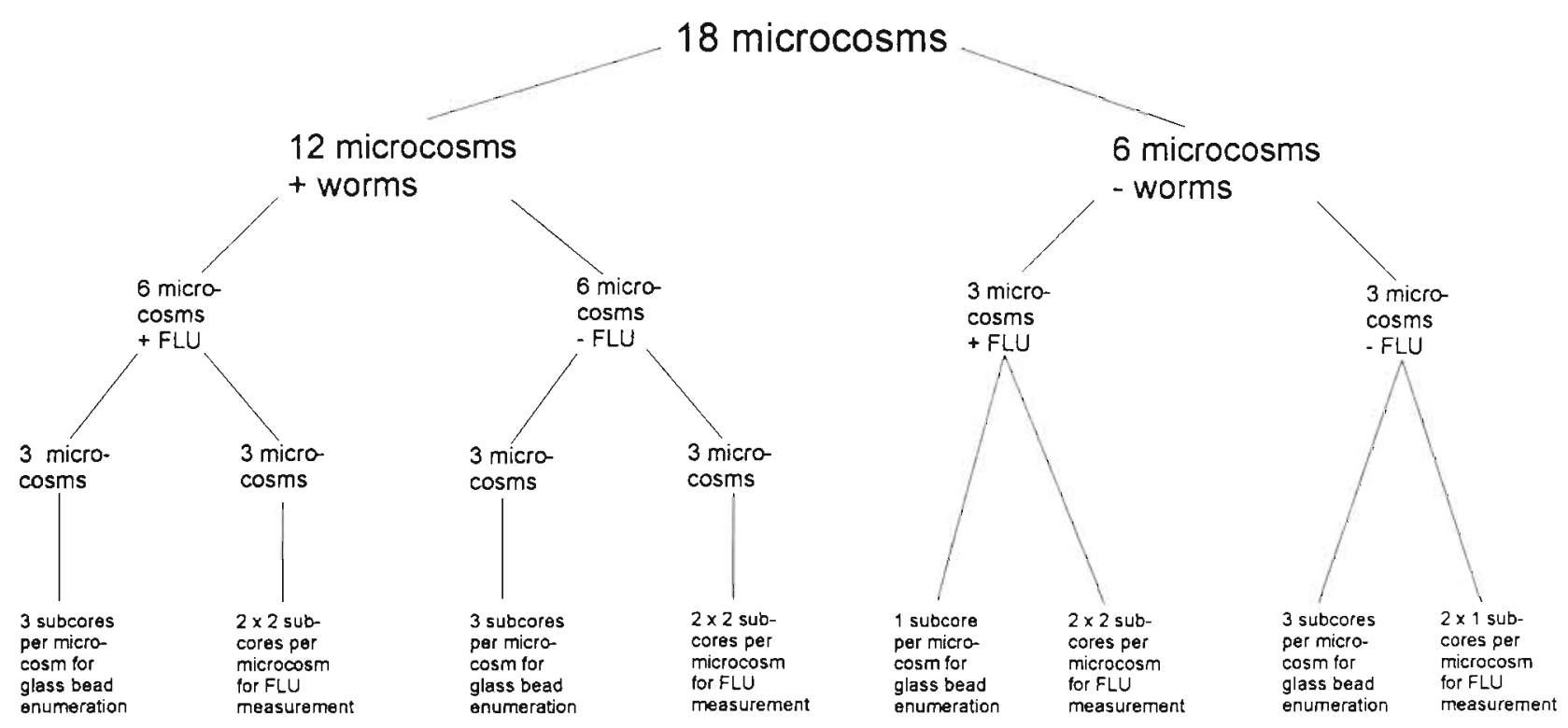

Fig. 1. Overall experimental design showing treatments and details for the subcoring of individual microcosms (FLU: fluoranthene)

replicate microcosms for 3 of the 4 treatments (+worms $+\mathrm{FLU}_{i}+$ worms $-\mathrm{FLU}_{i}$-worms $-\mathrm{FLU}_{i}$ Fig. 1). In one of the treatments (-worms +FLU), only 1 subcore was taken from each microcosm (Fig. 1). The subcores were frozen immediately. A stainless steel scalpel was used to cut the top centimeter into sections of $2 \mathrm{~mm}$ and the next centimeter into $3 \mathrm{~mm}$ sections. During sectioning, the subcores were kept frozen on dry ice. Each section was thawed with a few milliliters of water in a test tube and sonicated (Bransonic 5) for 5 to $10 \mathrm{~min}$. Preliminary tests showed that sonication completely disaggregated fecal pellets and other aggregates without affecting the glass beads.

The glass bead tracer was quantified after sediment from the subcore sections was allowed to settle through a column of water into a culture dish (Multidish, Nunclon, Denmark) in which they could be counted with an inverted microscope. The method (Moore 1973, modified by Laws 1983) originally consisted of settling the grains onto a gelatine-coated microscope slide (see Moore 1973) and was quite time consuming. Pilot experiments showed that using the culture dish instead of gelatine-coated microscope slides produced equivalent results in less time.

A 31 glass beaker (13 cm inner diam.) filled with tap water was used as a settling tank. The sample from each section of the subcores was poured into the tank, stirred gently but thoroughly with a vertical motion, and allowed to settle onto the bottom of the culture dish (see Moore 1.973). The culture dish was placed on a stand and held in place near the bottom of the settling tank by small lead sinkers. The grains were allowed to settle for 5 min. Calculations based on Stokes' law indicated that 5 min was enough time for spherical particles with a diameter of $30 \mu \mathrm{m}$ and a specific gravity of 2.5 to settle a distance of 15 to $20 \mathrm{~cm}$ through the water column. The water in the settling tank was then siphoned to below the culture dish. The culture dish was carefully removed and covered, and 4 to 6 wells of the culture dish (equal to ca 6 to $9 \%$ of the total) were counted (Olympus inverted microscope, 100x) for each sample. Subsamples within 1 subcore were counted blindly in arbitrary order to minimize potential bias. Within each subcore the results were summed to provide an estimate of the total inventory of glass beads. The inventory was used to normalize the number of counts from each depth interval. Thus, concentrations reported in graphs represent the proportion (i.e. relative frequency) at each depth interval of the total number of counted beads within 1 subcore (Wheatcroft 1992).

Sampling and analysis of particle-bound fluoranthene. Modified syringes (16 $\mathrm{mm}$ inner diameter) were used as subcores to take replicate subsamples at the beginning ( $t=0 \mathrm{~d}$ ) and at the end ( $t=22 \mathrm{~d}$ ) of the experiment. Two subcores were taken from each of the 3 microcosms of each treatment except one (-worms -FLU), from which only 1 subcore was taken at each of the 2 sampling times (Fig. 1). The subcores were immediately frozen and kept in darkness. The subcores were sectioned into $3 \mathrm{~mm}$ intervals down to $21 \mathrm{~mm}$ ( 7 sections). Deeper parts of the core were sampled from 2 additional $3 \mathrm{~mm}$ sections taken at 27-30 $\mathrm{mm}$ and $37-40 \mathrm{~mm}$. During the sectioning process, subcores were kept frozen on dry ice. Samples 
of $0.5 \mathrm{~g}$ (wet wt) sediment from each section were added to preweighed Pyrex extraction tubes and dried at $105^{\circ} \mathrm{C}$ for $20 \mathrm{~h}$ and weighed again to obtain dry weight.

The dried sediment sample from each section was extracted in $2 \mathrm{ml}$ of hexane. After hexane addition, samples were briefly vortexed, sonicated for $10 \mathrm{~min}$, and vortexed again for an additional $30 \mathrm{~s}$ before centrifugation for $10 \mathrm{~min}$ at $3000 \mathrm{rpm}(2170 \times \mathrm{g})$ (L. Kure pers. comm.). The extraction procedure was repeated 3 times and the supernatant was transferred to dark glass vials. An internal standard of biphenyl $198 \% \mathrm{GC}$ grade, Aldrich) was added in $2 \mathrm{ml}$ of hexane for the last extraction of each sample. Extracted samples were kept dark and cool until measured on a GC/MS with splitless injection (Hewlett Packard: HP 5890II gas chromatograph, HP 5971A mass spectrometer and HP data analyzer). A response factor was obtained after all subsamples within 1 subcore were run. The detection limit was $10 \mathrm{ppb}$. The extraction efficiency for fluoran- thene and biphenyl was $75 \%(\mathrm{SD}=16.6, \mathrm{n}=5)$ and $98 \%(\mathrm{SD}=4.1, \mathrm{n}=5)$ respectively.

\section{RESULTS}

\section{Observations and microcosm appearance}

There was a profound difference in the sediment appearance between microcosms with and without worms. Differences in the color of the sediment reflected differences in the redox state of the sediment (Rhoads 1974). The sediment in the microcosms without worms had a millimeter-thin layer of light brown (oxidized) sediment on top of black (anoxic) sediment. In the microcosms with worms, the light brown (oxidized) layer extended to 15 to $20 \mathrm{~mm}$. This layer consisted mainly of fecal pellets and the coarser texture was obvious to the eye (Fig. 2). A distinct separation of oxic and anoxic sediment was not as apparent as in the

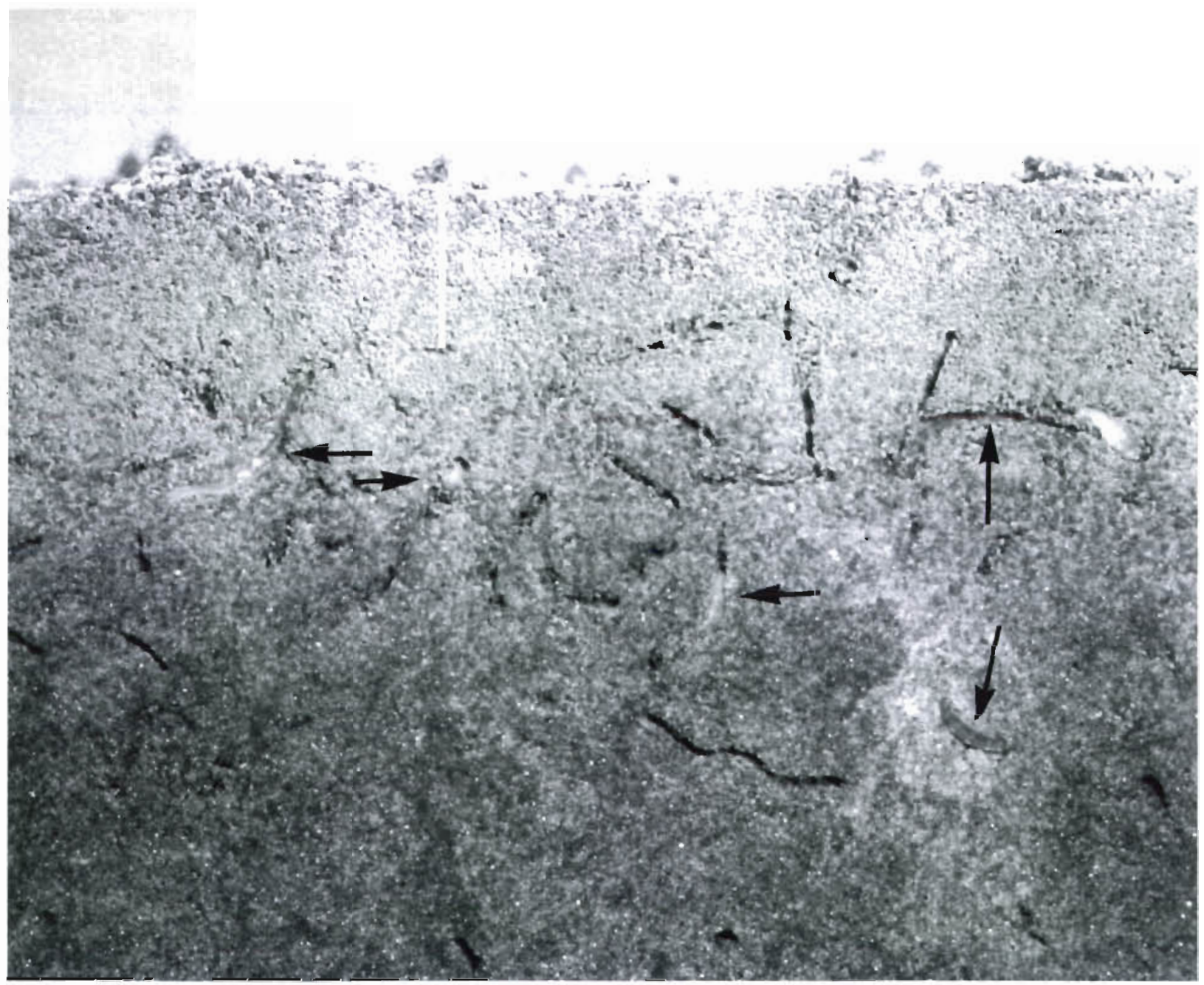

Fig. 2. Photograph of microcosm inhabited by Capitella sp. 1 showing 1 to $2 \mathrm{~cm}$ thick fecal pellet layer at the sediment-water interface. Arrows indicate individual worms in burrows. See text for detailed discussion 
uninhabited microcosms, and sediment near worm burrows often had an intermediate gray color. Burrows could be observed at all depths but occurred most frequently in the vicinity of the redox potential discontinuity (RPD), which was most distinct at the base of the pellet layer (Fig. 2). The burrows tended to be more vertically oriented within the upper pelletized layer and more horizontally oriented near the RPD. The tube openings were fairly uniform in distribution at the sediment surface and often appeared black. The black, protuding tubes constructed of recently defecated fecal pellets were in sharp contrast to the light brown intervening surface sediment consisting predominantly of older, collapsed pellet tubes.

Data on biomass, number of worms, average weight per worm and average worm length for each microcosm are given in Table 3 . There were no differences (ANOVA) in biomass $\left(F_{1,22}=0.25, \mathrm{p}=0.63\right)$, number of worms $\left(F_{1,22}=2.20, \mathrm{p}=0.17\right)$, average weight $\left(F_{1,22}=\right.$ $2.28, \mathrm{p}=0.12)$ and average length per worm $\left(F_{1,22}=\right.$ $0.28, p=0.61$ ) between microcosms with and without fluoranthene.

\section{Glass bead distribution}

There were distinct and characteristic vertical distributions of glass beads in microcosms with worms. All had a similar, non-diffusive profile as indicated by subsurface maxima in the upper $2 \mathrm{~cm}$ (Fig. 3). The beads were not counted at depths greater than $2 \mathrm{~cm}$ though there might have been a few more beads in some of the profiles. In microcosms without worms the glass beads remained in the top few millimeters (Fig. 4). A small fraction of the beads penetrated more deeply, perhaps due to sediment compaction during the coring procedure. We performed nested ANOVA in order to detect an effect of fluoranthene on the vertical glass bead distribution. This allowed effects due to individual microcosms (nested within treatment) as well as effect of the treatment (added fluoranthene) to be tested. Prior to the statistical analysis the cumulative frequencies were calculated for each subcore (typically 3 for each microcosm, Fig. 1), and the curves were fitted to the logistic equation

Table 3. Capitella sp. 1. Total biomass, total number of worms, and estimated mean weight and length of individual worms in treatment microcosms (FLU: fluoranthene). SD shown in parentheses. $n=6$. See text for details regarding calculations

\begin{tabular}{|ccccc|}
\hline & $\begin{array}{c}\text { Biomass } \\
\text { (mg dry wt) }\end{array}$ & Number & $\begin{array}{c}\text { Mean weight } \\
\text { (mg dry wt) }\end{array}$ & $\begin{array}{c}\text { Mean length } \\
\text { (mm) }\end{array}$ \\
\hline -FLU & $210.44(21.086)$ & $152.83(24.490)$ & $1.39(0.133)$ & $22.92(2.735)$ \\
+ FLU & $205.18(12.905)$ & $134.17(18.670)$ & $1.55(0.186)$ & $22.17(2.202)$ \\
\hline
\end{tabular}

+ FLU - FLU

Relative frequency of glass beads
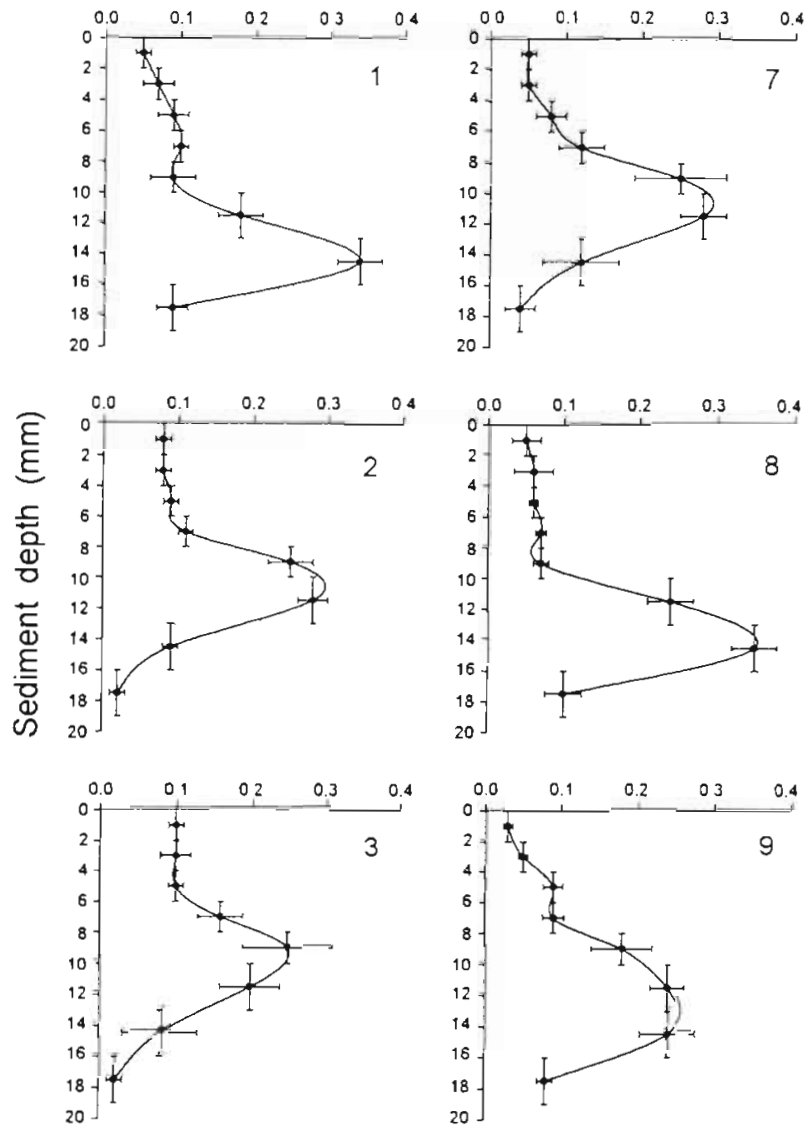

Fig. 3. Vertical distribution of glass beads in microcosms with worms and with (+FLU) and without (-FLU) added fluoranthene. Numbers in upper right of each profile are the original microcosm designations. All profiles except that for Microcosm 1 are the result of 3 subcores. Error bars are $\pm \mathrm{SE}$. $Y$-axis bars span the depth interval of sampling. Continuous line is a spline fit to the data

$$
Q=\frac{L x_{0}}{x_{0}+(L-x) e^{-k x}}
$$

where $Q$ is the cumulative frequency, $L$ is the asymptote $(-1), x_{0}$ is the intercept, $k$ is a constant and $x$ is depth into the sediment. Fig. 5 is an example curve fit. The first quartile $(Q=0.25)$, median $(Q=0.50)$, 3rd quartile $(Q=0.75)$, and the interquartile range $(I Q R)$ were determined for each subcore. Table 4 presents these values and the $\mathrm{R}^{2}$ for each subcore curve fit. The results of the statistical analysis are shown in Table 5 .

There was a significant $(p<0.05)$ effect of fluoranthene on the 1st quartile $\left(Q_{0.25}\right)$ and the median $\left(Q_{050}\right)$. The effect on the 3 rd quartile $\left(Q_{0.75}\right)$ was very 
+ FLU

- FLU

Relative frequency of glass beads
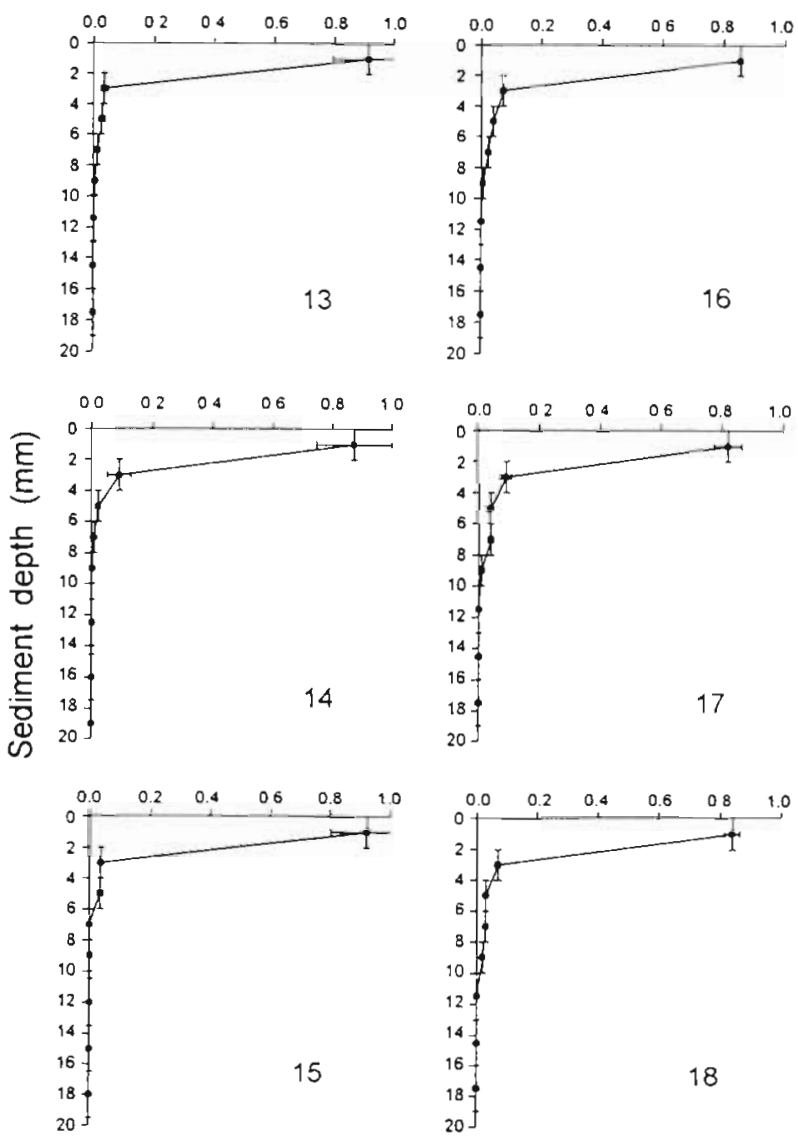

Fig. 4. Vertical distribution of glass beads in microcosms without worms and with (+FLU) and without (-FLU) added fluoranthene. Numbers in upper right of each profile are the original microcosm designations. All profiles except that for Microcosm 16 are the result of 3 subcores. Error bars are $\pm \mathrm{SE} . Y$-axis bars span the depth interval of sampling

close to significance as well $(\mathrm{p}=0.069)$ and indicates that the center of the vertical distribution differed in depth location and not in shape. This was confirmed by the lack of difference in the IQR.

A subduction rate $\left(S_{\mathrm{r}}\right)$ was estimated as

$$
S_{\mathrm{r}}=\frac{Q_{0.50}-Y_{0} 50}{t}
$$

where $t$ is time $(22 \mathrm{~d}), Q_{0.50}$ is the median $(\mathrm{mm})$ in microcosms with worms (Table 5) and $Y_{050}=$ $1.515 \mathrm{~mm}$. $Y_{0.50}$ was estimated by fitting each subcore profile in microcosms without worms (Fig. 4) to the exponential equation

$$
y=a+b e^{-x}
$$

calculating the median and taking the mean of all medians. The values of medians are shown in Table 6.

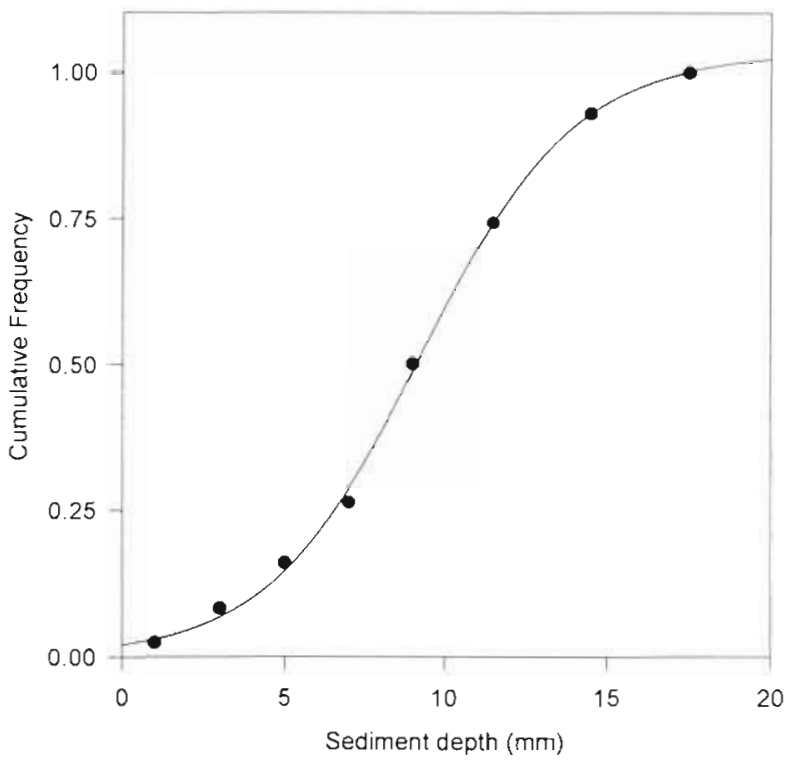

Fig. 5. Example curve fit for the depth distribution of the glass bead tracer in a worm-inhabited microcosm. Cumulative frequencies were fitted to a logistic equation (Eq. 1). See text for detailed explanation

Table 4. Cumulative frequency data for a logistic equation (Eq. 1) fit for each subcore. $Q_{0.25}=1$ st quartile, $Q_{0} s_{0}=$ median, $Q_{0.75}=3$ rd quartile and $Y Q R=$ interquartile range. All values (except $\mathrm{R}^{2}$ ) are in $\mathrm{mm}$. FLU: with fluoranthene; -FLU: with-

\begin{tabular}{|c|c|c|c|c|c|c|}
\hline \multicolumn{2}{|c|}{ Microcosm } & $\mathrm{R}^{2}$ & $Q_{0.25}$ & $Q_{0.5 n}$ & $Q_{075}$ & $I Q R$ \\
\hline \multirow[t]{8}{*}{$+\mathrm{FLU}$} & \multirow[t]{2}{*}{1} & 0.982 & 6.21 & 10.43 & 13.69 & 7.48 \\
\hline & & 0.996 & 6.77 & 9.83 & 12.58 & 5.81 \\
\hline & \multirow[t]{3}{*}{2} & 0.987 & 5.54 & 8.01 & 10.36 & 5.54 \\
\hline & & 0.993 & 5.04 & 7.84 & 10.48 & 5.45 \\
\hline & & 0.995 & 5.24 & 7.86 & 10.36 & 5.12 \\
\hline & \multirow[t]{3}{*}{3} & 0.995 & 3.75 & 6.36 & 8.89 & 5.14 \\
\hline & & 0.982 & 4.45 & 6.59 & 8.67 & 4.23 \\
\hline & & 0.991 & 5.66 & 8.85 & 11.73 & 6.07 \\
\hline \multirow[t]{9}{*}{$-F L U$} & \multirow[t]{3}{*}{7} & 0.997 & 6.00 & 7.88 & 9.73 & 3.73 \\
\hline & & 0.990 & 6.41 & 8.60 & 10.72 & 4.31 \\
\hline & & 0.997 & 6.57 & 9.78 & 12.65 & 6.09 \\
\hline & \multirow[t]{3}{*}{8} & 0.986 & 5.35 & 10.23 & 13.83 & 8.48 \\
\hline & & 0.993 & 8.64 & 11.14 & 13.37 & 4.73 \\
\hline & & 0.988 & 7.50 & 10.38 & 12.91 & 5.36 \\
\hline & \multirow[t]{3}{*}{9} & 0.994 & 6.78 & 9.96 & 12.76 & 5.98 \\
\hline & & 0.999 & 6.47 & 9.15 & 11.71 & 5.24 \\
\hline & & 0.999 & 6.52 & 9.10 & 11.57 & 5.05 \\
\hline
\end{tabular}
out fluoranthene

There was no significant (ANOVA, $\mathrm{p}=0.35$ ) difference in the medians $\left(Y_{050}\right)$ between microcosms. Fig. 6 is an example curve fit based on Eq. (3). The subduction rate $\left(S_{\mathrm{r}}\right.$ assumed constant with time) was significantly lower in microcosms with added fluoranthene (Table 7 , ANOVA, $\mathrm{p}<0.05$ ). $\mathrm{S}_{\mathrm{r}}$ was estimated to be $0.30 \mathrm{~mm} \mathrm{~d}^{-1}$ and $0.37 \mathrm{~mm} \mathrm{~d}^{-1}$ for microcosms with and without fluoranthene respectively. 
Table 5. Nested ANOVA results (microcosms nested within fluoranthene treatment) for tracer distribution measurements (Table 4, $\mathrm{n}=17$ ). FLU: fluoranthene treatment; $\operatorname{COSM}$ : microcosm within fluoranthene treatment. $p<0.05$, $\cdots p<0.01$

\begin{tabular}{|c|c|c|c|c|c|c|c|c|}
\hline \multirow{2}{*}{ Source } & \multicolumn{2}{|c|}{$Q_{025}$} & \multicolumn{2}{|c|}{$Q_{0.50}$} & \multicolumn{2}{|c|}{$Q_{0.75}$} & \multicolumn{2}{|c|}{$I Q R$} \\
\hline & FLU & COSM & FLU & $\operatorname{COSM}$ & FLU & COSM & FLU & $\operatorname{COSM}$ \\
\hline$d f$ & 1 & 4 & 1 & 4 & 1 & 4 & 1 & 4 \\
\hline MS & 6.33 & 1.33 & 5.47 & 3.87 & 4.50 & 5.70 & 0.32 & 1.57 \\
\hline$F$ & 8.72 & 1.83 & 8.87 & 6.28 & 4.07 & 5.16 & 0.24 & 1.17 \\
\hline$p$ & $0.013^{\circ}$ & 0.194 & $0.013^{\circ}$ & $0.007^{\cdots}$ & 0.069 & $0.014^{*}$ & 0.634 & 0.378 \\
\hline
\end{tabular}

Although the experimental conditions for each microcosm were designed to be identical, some variability among microcosms appeared to have influenced sediment mixing. The medians and the $Q_{0.75}$ values differed among microcosms (Table 5). The fact that the $Q_{0.75}$ was influenced by something other than fluoranthene may partly explain the diminished effect of FLU on this parameter. As indicated by the data summarized in Table 3 , there was some variation in worm population parameters at the end of the experiment, but no relationship was found among glass bead profile parameters (Table 4 ) and total biomass, number of worms, average weight and length of worms.

\section{Particle-bound fluoranthene}

The vertical distributions of particle-bound fluoranthene in microcosms with added fluoranthene, with and without Capitella sp. 1, are shown in Fig. 7. Fluoranthene concentrations in control microcosms (+worms-FLU; -worms -FLU) were below the detection limit of $10 \mathrm{ppb}\left(\mathrm{ng} \mathrm{g}^{-1}\right)$ and are not shown. The initial concentrations in the upper $3 \mathrm{~mm}$ of the fluoranthene contaminated subcores without worms ranged between 3 and $9 \mathrm{~g} \mathrm{~g}^{-1}$ whereas those from microcosms with worms varied between 6 and $10 \mathrm{~g} \mathrm{~g}^{-1}$. The starting concentrations of particle-bound fluoranthene were somewhat lower than expected, as we added a slurry with a fluoranthene concentration of $106 \mathrm{~g} \mathrm{~g}^{-1}$. The concentrations of fluoranthene in the deepest layers were never below the detection limit (as they were in the control cores). This is most likely an artifact caused by the coring procedure. The concentration of fluoranthene from each depth interval within a subcore was then summed to provide an estimate of fluoranthene inventory.

Fluoranthene profiles were very different in microcosms with and without Capitella sp. 1 at the end of the experiment. In the microcosms with worms almost all (94\%) fluoranthene was lost from the upper $3 \mathrm{~mm}$

Table 7 Nested ANOVA results for calculated subduction rates $\left(S_{r}\right)$ (microcosm within fluoranthene treatment). FLU. fluoranthene treatment; COSM: microcosm within fluoranthene treatment. $p<0.05, \cdots p<0.01$

\begin{tabular}{|lcccc|}
\hline Source & df & MS & $F$ & p \\
\hline FLU & 1 & 0.011 & 8.875 & $0.013^{\circ}$ \\
COSM & 4 & 0.008 & 6.282 & $0.007^{\circ}$ \\
\hline
\end{tabular}

Fig. 6. Example curve fit for the depth distribution of the glass bead tracer in a microcosm without worms. Control tracer profiles were fitted to an exponential decay equation (Eq. 3). See text for detailed explanation 


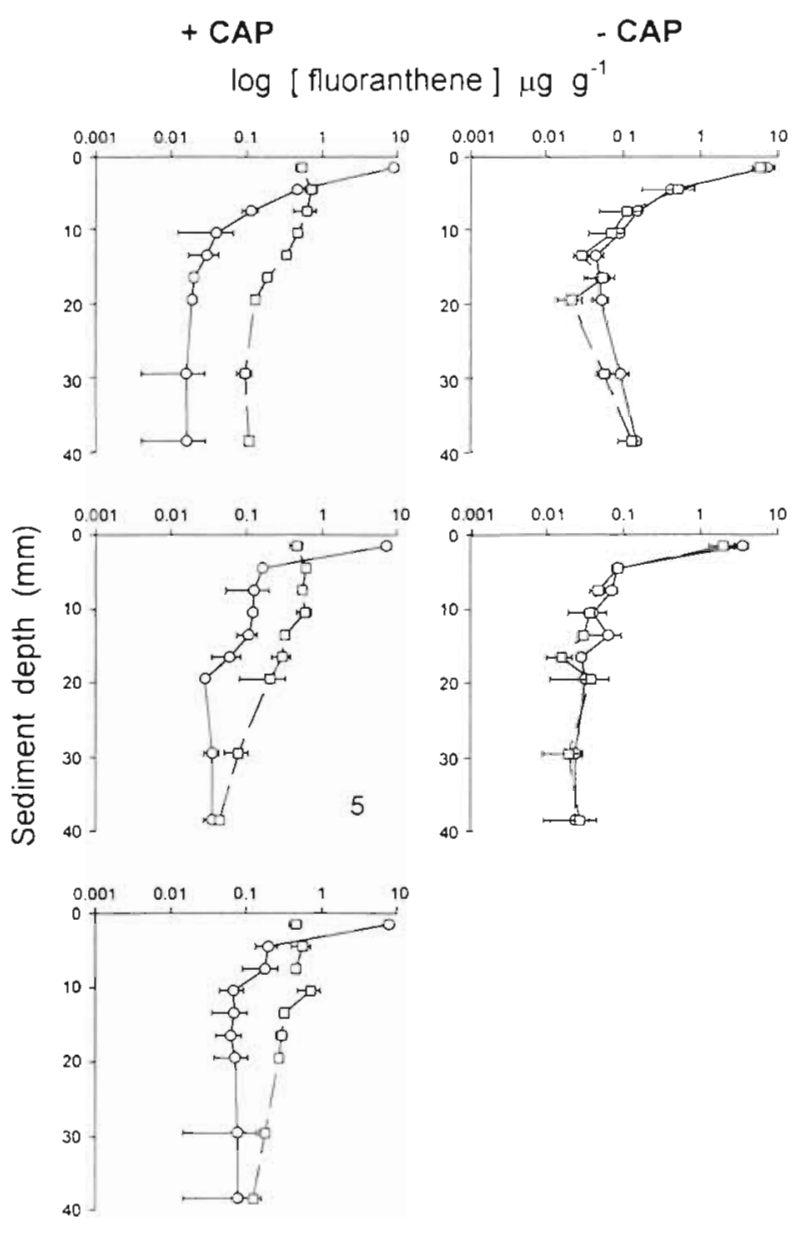

Fig. 7. Vertical distribution of particle-bound fluoranthene (+CAP: with worms; -CAP: without worms). All profiles are the result of 2 subcores. (O) Day O, ( $\square$ ) Day 22. Error bars are \pm range

Table 8. Estimated FLU losses from contaminated microcosms with and without Capitella sp. 1. Data tabulated as mean percent (SD shown in parentheses)

\begin{tabular}{|lcl|}
\hline Treatment & $\%$ total FLU loss & $\%$ loss $\mathrm{d}^{-1}$ \\
\hline Noworms $(\mathrm{n}=2)$ & $29(17.0)$ & $1.3(0.77)$ \\
Added worms $(\mathrm{n}=3)$ & $63(4.4)$ & $2.9(0.2)$ \\
\hline
\end{tabular}

layer. Some of the fluoranthene was transported to deeper layers ( 3 to $4 \mathrm{~cm}$ ) within the sediment, leading to an integrated loss of fluoranthene throughout the entire sediment column of $63 \%$ (Table 8 ). In the microcosms without worms a loss of fluoranthene of $30 \%$ from the upper $3 \mathrm{~mm}$ layer occurred (Fig. 7). A very small fraction of the added fluoranthene penetrated more deeply, presumably due to sediment compaction during the coring procedure. There was a total loss of $29 \%$ of the added fluoranthene in the uninhabited microcosms (Table 8). Thus the presence of Capitella sp. 1 nearly doubled the depth-integrated loss rate of fluoranthene.

\section{DISCUSSION \\ Bioadvective processes and feeding mode of Capitella sp. 1}

This experiment indicated that Capitella sp. 1 can mix sediment in a bioadvective and predominantly non-local fashion. This form of mixing is characterized by the appearance of distinct subsurface maxima, as was the case for the distribution of the glass bead tracer (Smith et al. 1986). Two types of feeding modes are responsible for non-local mixing. The first is conveyor-belt feeding sensu Rhoads (1974), where particles are ingested at depth and defecated on the sediment surface. The second is reverse conveyor-belt feeding, in which particles are ingested near the sediment surface and defecated at depth (Wheatcroft et al. 1994). The surface of microcosms inhabited by worms consisted of a layer of accumulated fecal pellets interspersed with numerous black, protuding tubes constructed of fecal pellets. These visual observations in combination with the glass bead tracer profiles strongly suggest conveyor-belt feeding as the primary mode of particle transport. Some diffusion-like dispersion of the subsurface peaks occurred, but this was much less important than bioadvective particle transport to the final particle distribution. The peak dispersion may be a result of the worms burrowing within the tracer layer, and infilling and/or collapse of tubes and burrows may be important as well (Boudreau \& Imboden 1987)

Biological mixing is often considered as being analogous to eddy diffusive mixing in hydrodynamics and is dependent upon a sufficient number and variety of small-scale mixing events. Models based on the 1dimensional biodiffusion analogy have been widely used to characterize and quantify sedimentary mixing processes (Guinasso \& Schink 1975, Aller 1982, DeMaster \& Cochran 1982, Wheatcroft 1992). One reason for this is that complex mechanisms of sediment mixing can be conveniently parameterized as a single factor, the biodiffusion coefficient $\left(D_{\mathrm{B}}\right)$. For most sediments, especially in relatively quiet coastal and deep sea environments, this coefficient is determined largely by bioturbation, although purely physical processes may often play an important role. At the outset of this study, the intention was to compute a biodiffusion coefficient using a diagenetic modelling approach for each tracer profile in order to have a comparable parameter of sediment mixing between conta- 
minated and uncontaminated microcosms which could then be used to compare the worm population response to the addition of fluoranthene.

Small opportunistic, pioneering species such as Capitella sp. 1 are thought to feed near the sediment surface, creating small-scale mixing events; whereas conveyor-belt or bioadvective mixing is thought to be more characteristic of larger species comprising mid to late successional-stage benthic communities (Rhoads $\&$ Boyer 1982). Prior to this study the mode of particle mixing by Capitella sp. 1 was unknown. Alongi (1985a, b) reported that $C$. capitata feeds on the sediment surface, and Tsutsumi (1990) stated that Capitella spp. were subsurface feeders. The situation of non-local mixing fits the biodiffusion analogue poorly, as the biodiffusion coefficient is based on a homogeneous, random mixing process. Thus to compare the particle mixing by Capitella in contaminated and uncontaminated sediments, we have taken a purely empirical approach and statistically analyzed the nature and rate of bioadvective mixing. The strength of the method is largely due to the very good fit of the glass bead cumulative frequency data to the logistic equation in combination with the ability of nested ANOVA to detect an effect of fluoranthene in spite of the variation among microcosms. The method we employed to obtain the cumulative frequencies is restricted to 1 subsurface peak per profile. Often multiple peaks can be seen on tracer profiles from conveyor-belt feeding; such reflections are a transient effect of conveyor belt recycling (Robbins 1986). In a study by Robbins et al. (1979), the conveyor-belt feeding oligochaete Tubifex tubifex created a bimodal tracer profile and with time the profile tended toward a more uniform distribution. It may be possible that Capitella sp. 1 fed more actively at a certain depth and that the tracer did not reach that depth within the duration of this experiment. Fisher et al. (1980) showed that that recycling of tracer most often occurred when it reached the depth to which conveyor-belt feeding activity of $T$. tubifex was confined. Rice (1986) observed the same phenomenon with Scoloplos spp. Here the tracer particles moved generally downward until they were returned to the sediment surface after entering the feeding zone of the worms. Another very plausible explanation of the pattern of the glass bead profile is that the worms rejected the glass bead tracer. The rejection may not have been complete as is evidenced by a distributional 'tail' of glass beads which was observed in the upper fecal pellet layer of all the tracer profiles (Fig. 3). Particle selectivity is very common among deposit feeders, may occur on the basis of size, shape, specific gravity, surface texture and chemical composition (Whitlatch 1974, Hylleberg 1975, Self \& Jumars 1978, Taghon 1982), and affects tracer profiles in a profound way
(Robbins 1986, Wheatcroft 1992, Wheatcroft et al. 1994). In a study of the polychaete Scoloplos spp., Rice et al. (1986) observed that the worms initially selected particles of high organic content probably as a result of selection of smaller particles. They suggested that the reason was an initially smaller size of the worms. Worms of the size used in our experiment are able to ingest particles up to approximately $80 \mu \mathrm{m}$ in diameter (Forbes 1984). Our initial aim for quantifying the glass beads was to classify bead profiles into 2 size fractions $(<80$ and $>80 \mu \mathrm{m})$ but the large size fraction $(>80 \mu \mathrm{m})$ turned out to be a very small proportion of the total. The use of glass beads as tracers has been criticized by Wheatcroft et al. (1994) because of their exotic properties, for instance the unnatural shape and surface, and glass beads are probably perceived as a poorer food source than natural sediment grains (Forbes \& Lopez 1990). Selective conveyor-belt feeding makes rejected particles move downward as a front which accumulates at the base of the feeding zone while selected particles are recycled to the sediment-water interface.

In situations in which particles and associated contaminants are supplied to the sediment surface at a constant rate and no loss is allowed, particle-selective conveyor-belt feeding can either reduce or enhance surface concentrations of particle-bound contaminants, depending on whether or not particles are preferentially rejected or consumed (Robbins 1986). Organic contaminants associate with small organicrich particles that are often selected by deposit feeders. Selective conveyor-belt feeding may thereby enhance surface concentrations of organic contaminants (Karickhoff \& Morris 1985). On the other hand the potential degradation may be enhanced as well, because the contaminant will be confined in the oxidized zone (see below). If particles with associated PAH are rejected, or otherwise become buried, the surface concentration will be diluted and the contaminant will build up in deeper sedimentary strata. The implications of this are that PAH will tend to be preserved by burial, as most are quite refractory under reduced conditions.

\section{Subduction rate and effect of fluoranthene}

Worms buried the glass beads at a rate of $0.37 \mathrm{~mm}$ $\mathrm{d}^{-1}$ (worm density of 30000 ind $\mathrm{m}^{-2}$ ) in the uncontaminated microcosms. The subduction rate was close to the $0.5 \mathrm{~mm} \mathrm{~d}^{-1}$ that has been found for another small conveyor-belt feeder, Tubifex tubifex (worm density of 50000 ind. $\mathrm{m}^{-2}$, Robbins et al. 1979). The size of the animals and population density are of course important for the magnitude of the subduction rate, but other factors such as temperature and sediment quality may be important as well (Rice 1986). Subduction due to 
conveyor-belt feeding can appear stratigraphically as an apparent sedimentation rate (Rice 1986). Considering the importance of burial by conveyor-belt feeding relative to sedimentation, the subduction rate of $0.37 \mathrm{~mm} \mathrm{~d}^{-1}$ gives a rate of $13.5 \mathrm{~cm} \mathrm{yr}^{-1}$, and exceeds even high sedimentation rates of 1 to $3 \mathrm{~cm} \mathrm{yr}^{-1}$ found in coastal marine environments (Olsen et al. 1981). Physical deposition and resuspension may be important and should be considered at a given time and place. The depth of erosion during a given wave resuspension event may vary considerably, but a useful reference point is to consider particles below the upper $1 \mathrm{~cm}$ thick surface layer to be no longer available for resuspension in most environments (Wheatcroft et al. 1994).

As pollutant stress can reduce rates of reworking or irrigation (Lee \& Swartz 1980), a potential effect of fluoranthene contamination was an alteration of subduction rate. In an experiment by Gilbert et al. (1994) the burrowing activity by Nereis diversicolor was reduced in response to oil (Arabian Light crude oil), resulting in $77 \%$ lower burial of tracer compared with uncontaminated sediment after $15 \mathrm{~d}$. After $45 \mathrm{~d}$ the difference was about $45 \%$. In this experiment the burial of glass beads was reduced by $19 \%$ in response to fluoranthene after $22 \mathrm{~d}$.

Thus the decreased subduction rate observed in our experiment is likely due to an effect of fluoranthene on worm feeding rates, resulting in reduced pellet production and surface sediment deposition, although we could not rule out behavioral changes resulting in a changed spatial patterning of defecation and burrowing. Augenfeld (1980) found fecal production was reduced by $70 \%$ when Abarenicola pacifica was exposed to oil-contaminated sediment (Prudhoe Bay crude oil). Feeding rate and rates of fecal production are more or less directly proportional to body size (Cammen 1980, Rice et al. 1986, Forbes 1989). Average worm lengths in the microcosms where the subduction rate was measured were significantly shorter in the contaminated microcosms, suggesting that growth rates may have been reduced under fluoranthene contamination (ANOVA, $p=0.04$ ). This could indicate that the growth of worms may have been reduced by fluoranthene, a prospect which requires further study. Alternatively, a reduced subduction of the glass bead tracer could be due to worms feeding selectively on the particle-bound fluoranthene and associated organic material within the zone of accumulated fecal pellets. As we made no direct measurements or observations of Capitella sp. 1 feeding depth, this possibility cannot be excluded. Nevertheless, given the appearance of the surface sediment and bead tracer profiles, it seems likely that worms fed predominantly at depths below the accumulated fecal pellet layer.

\section{Influence of Capitella sp. 1 on the fate of particle-bound fluoranthene}

The sediment concentrations of fluoranthene in this investigation were typical of those found in polluted aquatic environments (Johnson \& Larsen 1985, Shiaris \& Jambard-Sweet 1986). The concentration experienced by the worms may have been higher than the measured concentration in bulk sediment if they selectively ingested smaller organic and contaminant-rich sediment particles (Landrum \& Robbins 1990).

In microcosms with Capitella sp. 1, some of the particle-bound fluoranthene was mixed deeper into the sediment, but more than half of the fluoranthene was lost from the sediment, doubling the loss rates in uninhabited sediment. Three possible explanations exist for the loss of particle-bound contaminants in the presence of macrofauna: (1) enhanced flux to the waterphase, (2) enhanced microbial degradation and mineralization, and (3) uptake and metabolic degradation by macrofauna.

The presence of bioturbating infauna is known to increase the flux of contaminants to the water-phase. Clements et al. (1994) showed that the presence of Chironomus riparus increased the release of benz[a]pyrene (BAP) into the water-phase and that increased density of $C$. riparus further increased the release of BAP. Enhanced transport of solutes in porewater and enhanced fluxes across the sediment-water interface are possible due to increased porosity in combination with burrow irrigation (Aller 1982). Recycling contaminants to the sediment surface by conveyor-belt feeding may remobilize sediment contaminants into the water-phase. For example, the presence of Tubifex tubifex enhanced the discharge of hydrophobic pollutants from sediment to water by 4 to 6 -fold over a $90 \mathrm{~d}$ period (Karrickhoff \& Morris 1985). Given that Capitella sp. 1 can feed in conveyor-belt fashion and increase the porosity of the upper 15 to $20 \mathrm{~mm}$ by the build-up of a surficial layer of fecal pellets (this study, data not shown) and irrigation of burrows, there should be a great potential for increased flux of fluoranthene to the water column in the presence of worms.

The infaunal activities mentioned above may also stimulate microbial activity and growth (Yingst \& Rhoads 1980, Fry 1982, Aller \& Aller 1986). Increased porosity and deepening of the RPD is expected to enhance oxygen-dependent microbial processes such as the degradation of PA.H (Fry 1982). Oscillating redox conditions created by intermittent irrigation or displacement of particles may also have a positive effect on the mineralization of refractory organic matter (Aller 1994). The increased sediment-water interface will also benefit the microbial processes through enhanced exchange of dissolved nutrients into the sed- 
iment and metabolites or growth inhibitors out of the sediment (Yingst \& Rhoads 1980). The walls of tube and burrow structures have been shown to be sites for enhanced microbial activities due to the oxic-anoxic boundary and mucus-enriched zone (Aller \& Aller 1986). Alongi (1985a) found enhanced microbial activity on tubes produced by Capitella sp. 1. Several authors have reported stimulation of microbial activity and degradation of PAH/crude oil in sediments in the presence of macroinfauna (Gordon et al. 1978, Gardner et al. 1979, Bauer et al. 1988, McElroy et al. 1990, Gilbert et al. 1994), but the exact mechanisms responsible for the stimulation could not be determined.

In the microcosms without Capitella sp. 1, the loss of fluoranthene was relatively high $(29 \%)$, and the loss was confined to the oxidized top layer of the sediment, indicating that microbial processes may have been responsible for some of the loss. Gardner et al. (1979) studied the degradation of 4 specific PAH (anthracene, fluoranthene, benzo[a]pyrene and benz[a]anthracene) in the presence and absence of Capitella capitata. They found that the removal of PAH to the overlying water was less than $2 \%$ per week and that the microbial degradation was stimulated, especially in the surface sediments, but suggested that degradation by the worms could have been an important factor as well.

Spies et al. (1989) concluded that Capitella spp. were able to use petroleum as a carbon source. A recent study by Forbes et al. (1996) showed that Capitella sp. 1 took up fluoranthene but did not oxidize it to $\mathrm{CO}_{2}$, suggesting that fluoranthene was not used as an energy source. Instead fluoranthene was excreted as DOC, suggesting metabolic degradation. Other polychaetes have been shown capable of metabolizing PAH as well. For example, McElroy (1990) found that Nereis virens was capable of metabolizing benz[a]anthracene and benzo|a]pyrene. Holmer et al. (in press) found that fluoranthene profiles from sediments inhabited by Capiteila sp. 1 appeared very similar to those of the glass bead distribution in this experiment. Fluoranthene was buried and most of the added contaminant was recovered in their experiment. Several parameters were different from our experiment and could be responsible for the very different fate of fluoranthene. The time period was shorter (14 d), the sedimentary organic carbon content was more than twice as high $(5 \%)$, the concentration of sediment-bound fluoranthene was higher ( $50 \mathrm{ppm})$, and the density of worms $\left(10000 \mathrm{~m}^{-2}\right)$ was less than in our experiment. A lower worm density together with a higher sediment organic carbon content may result in less mobility of the particle-bound fluoranthene. Time may be an important factor controlling induction of microbial degradation (Cerniglia \& Heitkamp 1989). Several studies have shown that benthic infauna may try to avoid contaminated sediment and that avoidance is dependent on the concentration of the contaminant (Møhlenberg \& Kiørboe 1983, White \& Keilty 1988, Landrum et al. 1991). If worms are able to avoid particles with high concentrations of sedimentary contaminants, this difference in behavior will have serious implications for the fate of the contaminants. Sediment with associated contaminant would then be subducted and accumulate at the base of the feeding zone. This would act to preserve and potentially concentrate an organic contaminant in the sediment.

Acknowledgements. The authors thank J. P. Nielsen, B Larsen and $T$ Lund for assistance with the fluoranthene measurements and A. G. Sorensen for laboratory assistance. We are grateful to L. Jeppesen for analyzing the particle size distribution of the sediment and to E. S. Jensen for analyzing $P O C$ and PON. In addition, we give our special thanks to $\mathrm{L}$ Kure for the use of her extraction method and to K. Scharck for his contribution to this work. This work was supported by a grant from the Danish National Science Council, No. 11 1047-1 to T.L.F.

\section{LITERATURE CITED}

Aller JY, Aller RC (1986) Evidence for localized enhancement of biological activity associated with tube and burrow structures in deep-sea sediments at the HEBBLE site, western North Atlantic. Deep Sea Res 33:755-790

Aller RC (1982) The effects of macrobenthos on chemical properties of marine sediments and overlying water. In: McCall PL, Tevesz MJS (eds) Animal-sediment relations. Plenum Press, New York, p 53-102

Aller RC (1994) Bioturbation and remineralization of sedentary organic matter: effects of redox oscillation. Chem Geol 114:331-345

Alongi DM (1985a) Microbes, meiofauna and bacterial productivity on tubes constructed by the polychaete Capitella capitata. Mar Ecol Prog Ser 23:207-208

Alongi DM (1985b) Effect of physical disturbance on population dynamics and trophic interactions among microbes and meiofauna. J Mar Res 43:351-364

Augenfeld JM (1980) Effects of Prudhoe Bay crude oil contamination on sediment reworking rates of Abarenicola pacifica. Mar Environ Res 3:307-313

Bauer JE, Capone DG (1985) Degradation and mineralization of the polycyclic aromatic hydrocarbons anthracene and naphthalene in intertidal marine sediments. Appl Environ Microbiol 50:81-90

Bauer JE, Kerr RP, Bautista MF, Decker CJ, Capone DG (1988) Stimulation of microbial activities and polycyclic aromatic hydrocarbon degradation in marine sediments inhabited by Capitella capitata. Mar Environ Res 25:63-84

Boudreau BP, Imboden DM (1987) III. Mathematics of tracer mixing in sediments: the theory of non-local mixing in sediments. Am J Sci 287.693-719

Cammen LM (1980) Ingestion rate: an empirical model for aquatic deposit feeders and detrivores. Oecologia 44: $303-310$

Cerniglia CE, Heitkamp MA (1989) Microbial degradation of polycyclic aromatic hydrocarbons (PAH) in the aquatic environment. In: Varanasi U (ed) Metabolism of polycyclic 
aromatic hydrocarbons in the aquatic environment. CRC Press, Inc, Boca Raton, p 41-68

Clements WH, Oris JT, Wissing TE (1994) Accumulation and food chain transfer of flouranthene and benzo[a]pyrene in Chironomus riparius and Lepomis macrochirus. Arch Environ Contam Toxicol 26:261-266

DeLaune RD, Patrick WH, Casselman ME (1981) Effect of sediment $\mathrm{pH}$ and redox conditions on degradation of benzo(a)pyrene. Mar Pollut Bull 7:251-253

DeMaster DJ, Cochran JK (1982) Particle mixing rates in the deep-sea determined from excess ${ }^{210} \mathrm{~Pb}$ and ${ }^{32} \mathrm{Si}$ profiles. Earth Planet Sci Lett 61:257-271

DeWitt TH, Ozretich RJ, Swartz RC, Lamberson JO, Schultz DW, Ditsworth GR, Jones JKP, Hoselton L, Smith LM (1992) The influence of organic matter quality on the tox1city and the partioning of sediment-associated fluoranthene. Environ Toxicol Chem 11:197-208

Eisler R (1987) Polycyclic aromatic hydrocarbon hazards to fish, wildife and inverterbrates: a synoptic review. US Fish Wildl Serv Biol Rep 85 (111)

Fisher JB, Lick WJ, MCCall PJ, Robbins JA (1980) Vertical mixing of lake sediments by tubificid oligochaetes. J Geophys Res 85(C7):3997-4006

Forbes TL (1984) Aspects of the feeding biology of Capitella capitata species 1 . measurements of ingestion selectivity, egestion rate and absorption efficiency. MSc thesis, State University NY, Stony Brook

Forbes TL (1989) The importance of size-dependent processes in the ecology of deposit-feeding benthos. In: Lopez G, Taghon $G$, Levinton $J$ (eds) Ecology of marine deposit feeders. Springer, New York, p 172-200

Forbes TL, Lopez GR (1990) The effect of food concentration, body size, and environmental oxygen tension on the growth of the deposit-feeding polychaete, Capitella species 1. Limnol Oceanogr 35:1535-1544

Forbes VE, Forbes TL (1994) Ecotoxicology in theory and practice. Chapman \& Hall, London

Forbes VE, Forbes TL, Holmer M (1996) Inducible metabolism of fluoranthene by the opportunistic polychaete, Capitella sp 1. Mar Ecol Prog Ser 132:63-70

Fry JC (1982) Interactions between bacteria and benthic invertebrates. In: Dedwell DB, Brown CM (eds) Sediment microbiology. Academic Press, New York, p 171-201

Gardner WS, Lee RF, Tenore KR, Smith LW (1979) Degradation of selected polycyclic aromatic hydrocarbons in coastal sediments: importance of microbes and polychaete worms Capitella capitata. Water Air Soil Pollut 11: $339-348$

Gilbert F, Rivet L, Bertrand JC (1994) The in vitro influence of the burrowing polychaete Nereis diversicolor on the fate of petroleum hydrocarbons in marine sediments. Chemosphere 29:1-12

Gordon DC, Dale J, Keizer PD (1978) Importance of sediment working by the deposit-feeding polychaete Arenicola marna on the weathering rate of sediment-bound oil. J Fish Res Bd Can 35:591-603

Grassle JF, Grassle JP (1974) Oppotunistic life histories and genetic systems in marine benthic polychaetes. J Mar Res 32:253-284

Gunnasso NL, Schink DR (1975) Quantitative estimates of bılogical mixing rates in abyssal sediment. J Geophys Res 80:3032-3043

Hambrick GA III, Delaune RD, Patrick WH Jr (1980) Effect of estaurine sediment $\mathrm{pH}$ and oxidation-reduction potential on microbial hydrocarbon degradation. Appl Environ Microbiol 40:365-369

Helmstetter MF, Alden RW III (1994) Release rates of poly- nuclear aromatic hydrocarbons from natural sediments and their relationship to solubility and octanol-water partitioning. Arch Environ Contam Toxicol 26:282-291

Holmer M. Forbes VE. Forbes TL (in press) The impact of the polychaete Capitella sp. I on microbial activity in an organic-rich marine sediment contaminated with the polycyclic aromatic hydrocarbon fluoranthene. Mar Biol

Hylleberg J (1975) Selective feeding by Abarenicola vagabunda and a concept of gardening in lugworms Ophelia 14:113-137

Jensen ES (1991) Evaluation of automated analysis of ${ }^{15} \mathrm{~N}$ and total $\mathrm{N}$ in plant material and soil. Plant Soil 133:83-92

Johnson AC, Larsen PF (1985) The distribution of polycyclic aromatic hydrocarbons in the surficial sediments of Penobscot Bay (Maine, USA) in relation to possible sources and to other sites worldwide. Mar Environ Res 15: $1-16$

Karickhoff SW (1981) Semi-empirical estimation of sorption on hydrophobic pollutants on natural sediments and soils. Chemosphere 10:833-846

Karickhoff SW, Morris KR (1985) Impact of tubificid oligochaetes on pollutant transport in bottom sediments. Environ Sci \& Technol 19:51-56

Krantzberg G (1985) The influence of bioturbation on physi$\mathrm{cal}$, chemical and biological parameters in aquatic environments: a review. Environ Pollut Ser A Ecol Biol 39 $99-122$

Landrum PF, Eadie BJ, Faust WR (1991) Toxicokinetics and toxicity of a mixture of sediment-associated polycyclic aromatic hydrocarbons to the amphipod Diporeia sp. Environ Toxicol Chem 10:35-46

Landrum PF, Robbins JA (1990) Bioavailability of sedimentassociated contaminants to benthic invertebrates. In: Baudo R, Giesy JP, Muntau H (eds) Sediments: chemistry and toxicity of in-place pollutants. Lewis Publishers, Inc, Ann Arbor, Ml, p 237-263

Laws RA (1983) Preparing strewn slides for quantitative microscopical analyses: a test using calibrated microspheres. Micropaleontology 29:60-65

Lee H II, Swartz RC (1980) Biological processes affecting the distribution of pollutants in marine sediments. Part II: biodeposition and bioturbation. In: Baker RA (ed) Contaminants and sediments, $\mathrm{Vol}_{\mathrm{O}}$ 2. Ann Arbor Science, MI, p 555-606

Malins DC, McCain BB, Brown DW, Varanasi U, Krahn MM, Myers MS, Chan S (1987) Sediment-associated contaminants and liver diseases in bottom-dwelling fish. Hydrobiologia 149:67-74

McElroy AE (1990) Polycyclic aromatic hydrocarbon metabolism in the polychaete Nereis virens. Aquat Toxicol 18: $35-50$

McElroy AE, Farrington JW, Teal JM (1990) Influence of mode of exposure and the presence of a tubiculous polychaete on the fate of benzolalanthracene in the benthos. Environ Sci \& Technol 24:1648-1655

Metcalfe CD, Cairns VW, Fitzsimons JD (1988) Experimental induction of liver tumours in rainbow trout (Salmo gairdneri) by contaminated sediment from Hamilton Habour, Ontario. Can J Fish Aquat Sci 45:2161-2167

Møhlenberg F, Kiørboe T (1983) Burrowing and avoidance behaviour in marine organisms exposed to pesticide contaminated sediment. Mar Pollut Bull 14:57-60

Moore TC (1973) Method of randomly distributing grains for microscopic examination. J Sediment Petrol 43:904-906

Neff JM (1979) Polycyclic aromatic hydrocarbons in the aquatic environment: sources, fates and biological effects. Applied Science, London 
Neff JM (1985) Polycyclic aromatic hydrocarbons. In: Rand GM, Petrocelli SR (eds) Fundamentals of aquatic toxicology. Hemisphere, New York, p 416-454

Olsen CR, Simpson HJ, Ping TH, Bopp RF, Trier RM (1981) Sediment mixing and accumulation rate effects on radionuclide depth profiles in Hudson estuary sedıments. J Geophys Res 86:11020-11028

Oyenekan JA (1983) Production and population dynamics of Capitella capitata. Arch Hydrobiol 98:115-126

Reynoldson TB (1987) Interactions between sediment contaminants and benthic organisms. Hydrobiologia 149: $53-66$

Rhoads DC (1974) Organism-sediment relations on the muddy sea floor. Oceanogr Mar Biol Annu Rev 12:263-300

Rhoads DC, Boyer LF (1982) The effects of marine benthos on physical properties of sediments. A successional perspective. In: McCall PL, Tevesz MJS (eds) Animal-sediment relations. Plenum Press, New York, p 53-102

Rice DL (1986) Early diagenesis in bioadvective sediments: relationships between the diagenesis of beryllium-7, sediment reworking rates, and the abundance of conveyorbelt deposit-feeders. J Mar Res 44:149-184

Rice DL, Bianchi TS, Roper EH (1986) Experimental studies of sediment reworking and growth of Scoloplos spp. (Orbiniidae: Polychaeta). Mar Ecol Prog Ser 30:9-19

Robbins JA (1986) A model for particle-selective transport of tracers in sediments with conveyor belt deposit feeders. J Geophys Res 91:8542-8558

Robbins JA, McCall PL, Fisher JB. Krezoski JR (1979) Effect of deposit feeders on migration of cesium-137 in lake sediments. Earth Planet Sci Lett 42:277-287

Sanders HL, Grassle JF, Hampson GR, Morse LS, GarnerPrice S, Jones CC (1980) Anatomy of an ojl spill: long-term effects from the grounding of the barge Florida off West Falmouth, Massachusetts. J Mar Res 38:265-380

Self RFL, Jumars PA (1978) New resource axes for deposit feeders? J Mar Res 36:627-641

Shiaris MP (1989) Seasonal biotransformation of naphtalene, phenanthrene and benzo[a]pyrene in surficial estuarine sediments. Appl Environ Microbiol 55:1391-1399

Shiaris MP, Jambard-Sweet D (1986) Polycyclic aromatic hydrocarbons in surficial sediments of Boston Harbour, Massachusetts, USA. Mar Pollut Bull 17:469-472

Smith JN, Boudreau BP, Noshkin V (1986) Plutonium and ${ }^{210} \mathrm{~Pb}$ distributions in northeast Atlantic sediments: subsurface anomalies caused by non-local mixing. Earth Planet Sci Lett $81: 15-28$

This article was submitted to the editor
Spies RB, Bauer JE, Hardin D (1989) Stable isotope study of sedimentary carbon utilization by Capitella spp.: effects of two carbon sources and geochemical conditions durnng their diagenesis. Mar Biol 101:69-74

Swartz RC, Schultz DW, DeWitt TH, Ditsworth GR, Lamberson JO (1990) Toxicity of fluoranthene in sediment to marine amphipods: a test of the equilibrium partitioning approach to sediment quality criteria. Environ Toxicol Chem 9:1071-1080

Taghon GL (1982) Optimal foraging by deposit-feeding invertebrates: roles of particle size and organic coating. Oecologia 52:295-304

Tsutsumi H (1987) Population dynamics of Capitella capitata (Polychaeta: Capitellidae) in an organically polluted cove. Mar Ecol Prog Ser 36:139-149

Tsutsumi H (1990) Population persistence of Capitella spp. (Polychaeta; Capitellidae) on a mud flat subject to environmental disturbance by organic enrichment. Mar Ecol Prog Ser 63:147-156

Tsutsumi H, Fukunaga S, Fujita N, Sumida M (1990) Relationship between growth of Capitella spp. and organic enrichment of the sediment. Mar Ecol Prog Ser 63:157-162

Tsutsumi $H$, Kikuchi $T$, Tanaka $M$, Higashi $T$, Imasaka $K$ Miyasaki $M$ (1991) Benthic faunal succession in a cove organically polluted by fish farming. Mar Pollut Bull 23: $233-238$

Weston DP (1990) Hydrocarbon bioaccumulation from contaminated sediment by the deposit-feeding polychaete Abarenicola pacifica. Mar Biol 107:159-169

Wheatcroft RA (1992) Experimental tests for particle sizedependent bioturbation in the deep ocean. Limnol Oceanogr 37:90-104

Wheatcroft RA, Olmez I, Pink FX (1994) Particle bioturbation in Massachusetts Bay: preliminary results using a new deliberate tracer technique. J Mar Res 52:1129-1150

White DS, Keilty TJ (1988) Burrowing avoidance assays of contaminated Detroit River sediments, using the freshwater oligochaete Stylodrilus heringianus (Lumbriculidae). Arch Environ Contam Toxicol 17:673-681

Whitlatch RB (1974) Food-resource partitioning in the deposit feeding polychaete Pectinaria gouldii. Biol Bull (Woods Hole) 147:227-235

Yingst JY, Rhoads DC (1980) The role of bioturbation in the enhancement of bacterial growth rates in marine sediments. In: Tenore KR, Coull BC (eds) Marine benthic dynamics. University of South Carolina Press, Georgestown, p 407-422

Manuscript first received: December 27, 1995

Revised version accepted: July 11, 1996 